\title{
Editorial
}

\section{Advancements in Design, Analysis, and Retrofitting of Structures Exposed to Blast}

\author{
Chiara Bedon, ${ }^{1}$ Claudio Amadio, ${ }^{1}$ Li Chen, ${ }^{2}$ Vasant Matsagar, ${ }^{3}$ \\ Frank Wellershoff, ${ }^{4}$ and Xihong Zhang ${ }^{5}$ \\ ${ }^{1}$ University of Trieste, Trieste, Italy \\ ${ }^{2}$ PLA University of Science and Technology, Nanjing, China \\ ${ }^{3}$ Indian Institute of Technology, Delhi, India \\ ${ }^{4}$ HafenCity University, Hamburg, Germany \\ ${ }^{5}$ Curtin University, Perth, WA, Australia
}

Correspondence should be addressed to Chiara Bedon; bedon@dicar.units.it

Received 31 August 2016; Accepted 31 August 2016

Copyright (C) 2016 Chiara Bedon et al. This is an open access article distributed under the Creative Commons Attribution License, which permits unrestricted use, distribution, and reproduction in any medium, provided the original work is properly cited.

The objective of this special issue is to provide an overview on the current trends and recent advancements in terms of design, analysis, experimental testing, and retrofitting of structural systems and assemblies exposed to exceptional loads such as explosions.

Protection of constructed facilities from damaging natural hazards and exceptional loads, as known, has recently become an important issue in common practice. Besides the generalized goal of protective constructions to minimize injuries and improve the probability of survival of people, after the bombing of the Oklahoma Federal Building (1995), the blast design of structures has become a fundamental requirement, so that most of the actual strategic buildings and infrastructures must guarantee appropriate levels of blast resistance. Compared to quasistatic ordinary loads or conventional hazards such as wind gusts, earthquakes, floods, or moderate impacts, blast events are typically characterized by a large-scale, extremely rapid, and sudden release of energy, generally in the order of thousandths of seconds or milliseconds. As a result, specific design methods and advanced computational models able to properly include the effects of several aspects, like high strain rates, nonlinear inelastic material behaviors, and time-dependent deformations, are strictly required. The vulnerability assessment of a given structure exposed to explosive events, moreover, should properly take into account the interaction of the assigned blast wave and the targeted system, as well as the uncertainties implicitly related to the blast pressure description.

Finite-Element (FE) and Computational Fluid Dynamics (CFD) numerical simulations, in this sense, can represent the first tool for the dynamic analysis of a given structural assembly under air blast waves, as alternative to time and cost consuming far field or laboratory experimental tests. The implementation of both the numerical approaches, however, could result in being particularly difficult in the case of complex structural configurations. Several key input parameters, moreover, are strictly required in them for accurate estimations and appropriate risk analyses.

In some cases, special retrofitting techniques, as well as the implementation of novel passive/active control systems, could be also required to guarantee appropriate levels of resistance in a given assembly subjected to blast events, especially in the case of existing buildings or extremely vulnerable structural typologies.

A multidisciplinary approach, including fluid-structure interaction theories, material sciences concepts, and technological innovation, is thus essential.

The revised papers sent for production and included in the final special issue booklet are related to various topics, such as the blast performance of reinforced concrete structures and bridges, as well as masonry systems or structural glass windows and facades. Careful consideration is also paid 
for the performance of special materials under blast impacts, such as polymeric foams or bioinspired materials able to act as protective coatings during explosive events. Additional details and information on the published papers are provided in the following paragraphs.

In the paper by L. Lantz et al., a detailed state-of-the art review on the actual possibilities for the blast protection of unreinforced masonry walls is presented. Careful consideration, based on some recent literature contributions, is given both to the current mitigation techniques and to the available experimental testing methods for the assessment of the blast vulnerability and resistance of masonry structures. Possible solutions including fiber reinforced polymer (FRP) composites and polyuria, as well as steel sheets or aluminum foams, are then critically discussed.

M. Andreou et al. investigated the blast effects on a twospan, reinforced concrete bridge representative of a highway overpass. The dynamic response of the bridge under a near distance explosive event is first deeply investigated by means of a refined, full three-dimensional numerical model. A simplified, practical to use, modelling methodology is then proposed as a useful tool for a rational but fast evaluation of blast effects on structures. The potential of such simplified approach is emphasized by application to the reinforced concrete bridge object of study.

Attention to the numerical investigation of concrete structures under blast loads is also given by G. Hu et al., with careful consideration for the blast performance of multilayer concrete slabs. The numerical investigations are carried out via computationally advanced and refined three-dimensional models implemented in the hydrocode AUTODYN. Based on parametric numerical investigations and validation towards experimental test results, the potentials and limits of the RHT concrete model are emphasized in the paper. Modified input parameters are also proposed for the same RHT method, in order to obtain a more realistic postpeak softening behavior for concrete under tension and compression.

Numerical models, as known, represent in current practice a high potential for researchers and designers, since allowing simulating even mechanical and geometrical complex structural systems and assemblies under a multitude of boundary and loading conditions. As such, however, careful attention should be given to several aspects, first of all, especially in the case of explosive loads, the implemented damage models for materials, but also the boundary conditions and any possible mechanical interaction between the model components. These topics, if not properly addressed, can result in misleading and even unsafe results, especially in case no provisions or recommendations are provided to design practitioners and software users.

In this regard, the paper by M. Larcher et al. focuses on the design of blast resistant structural glass windows and facades, with careful attention for the role and the requirements of numerical models for such systems. The paper attempts to give a first idea of a possible standardization concerning numerical simulations. Attention is drawn to the representation of the blast loading and to the proper description of the behavior of the material of the mentioned products, to the geometrical meshing of the model components, and to the modelling of the connections between the glazing system components and between the glass façade and the structural background. The current need to validate such numerical models against reliable experimental test data, some of which are indicated, is also underlined.

Two of the published papers are finally related to research projects aimed at exploring the potential and feasibility of innovative materials able to act as protective coatings for structures and buildings subjected to explosive loads. In the paper from H. Ousji et al., for example, an extended experimental investigation is carried out on sacrificial cladding composed of three different types of polymeric foams (i.e., expanded polystyrene foam, closed-cell polyurethane, and open-cell polyurethane). These foams are expected to be introduced between the main structures and a front plate, so that the crushable core could work as active sacrificial cladding able to protect the main structures themselves. The experimental tests are critically discussed, giving some useful provisions in terms of performance of such foams and highlighting the potential/limits of the explored solutions.

Y. Sun et al., finally, present a review paper aimed at providing state of the art on the mechanisms behind the performance of abalone nacre under several loading conditions, including shear, uniaxial tension, compression, and bending. When used in abalone shells as inner layer, nacre exhibits typically high stiffness and toughness properties, hence suggesting the development of bioinspired building materials able to provide excellent performances under impact loads. This potential is also emphasized on the base of experimental test results. A successful application, in particular, is expected in cement-based and clay-based composite materials.

In conclusion, some final considerations on the full special issue project are given.

\section{Acknowledgments}

First of all, all the authors are gratefully acknowledged for their active contribution to the call for papers. The hope is that the readers could find fruitful and high quality research topics in the published papers. Peer reviewers, in this regard, have a key role in the collection of advancing, high quality scholarly journals. As such, the guest editors of the special issue would like to extend special thanks to the reviewers who carefully read all the submitted articles. Their observations and comments represented a great support, both to the authors, to improve the quality of the original papers, and to the guest editors, to make objective decisions with regard to the excellence of the submitted research papers. A final acknowledgement is also extended by the Lead Guest Editor, Dr. Bedon, to the full team of guest editors, for the support provided in the last months through the full process of submission and promotion of the call for papers, up to the publication of the special issue booklet in the journal.

Chiara Bedon Claudio Amadio Li Chen

Vasant Matsagar Frank Wellershoff Xihong Zhang 


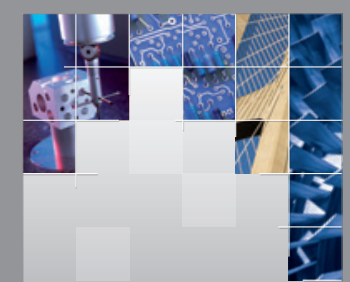

\section{Enfincering}
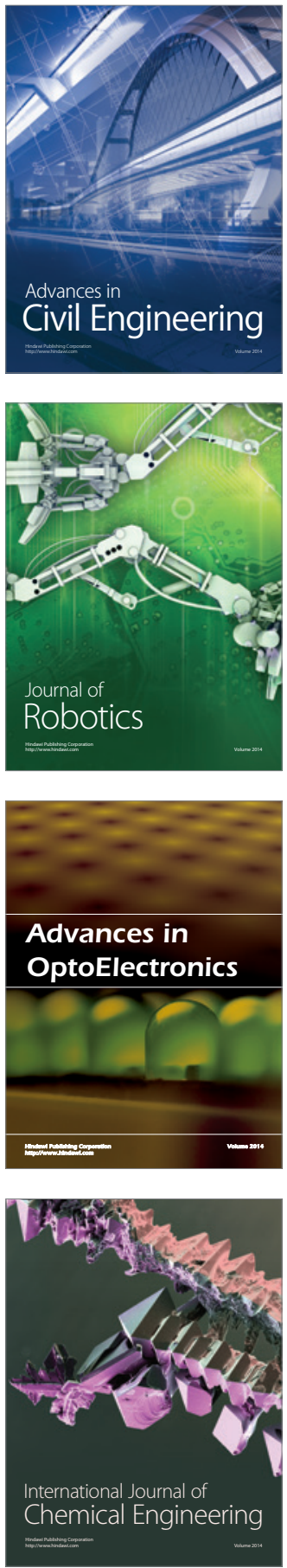

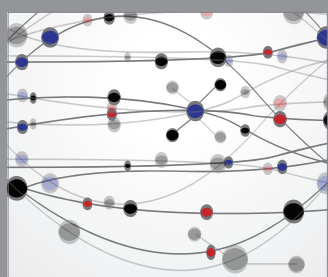

The Scientific World Journal

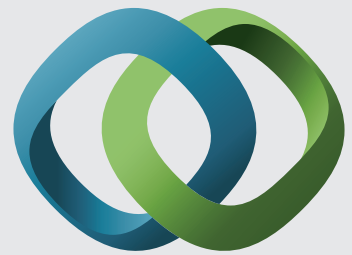

\section{Hindawi}

Submit your manuscripts at

http://www.hindawi.com
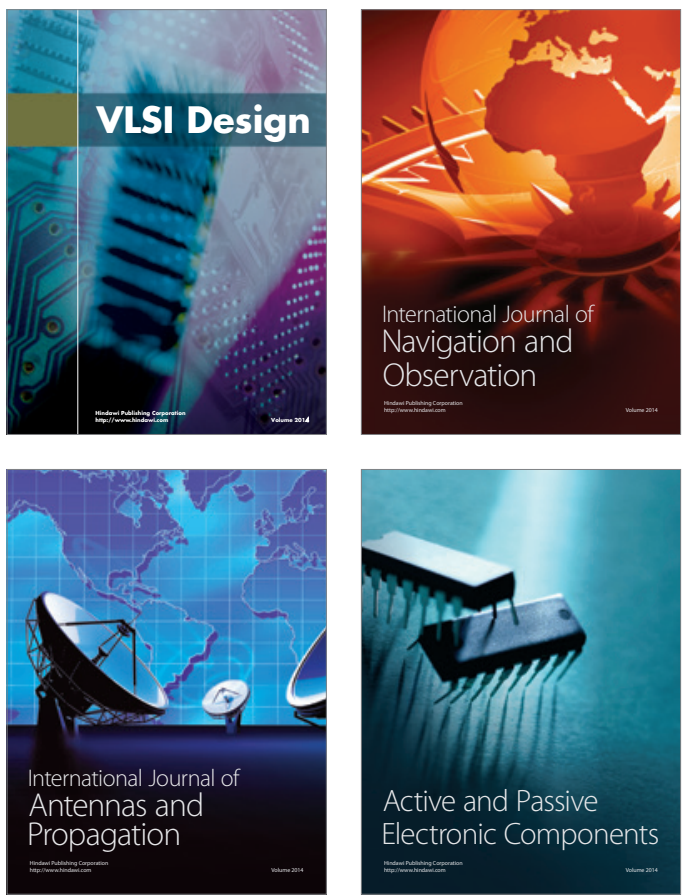
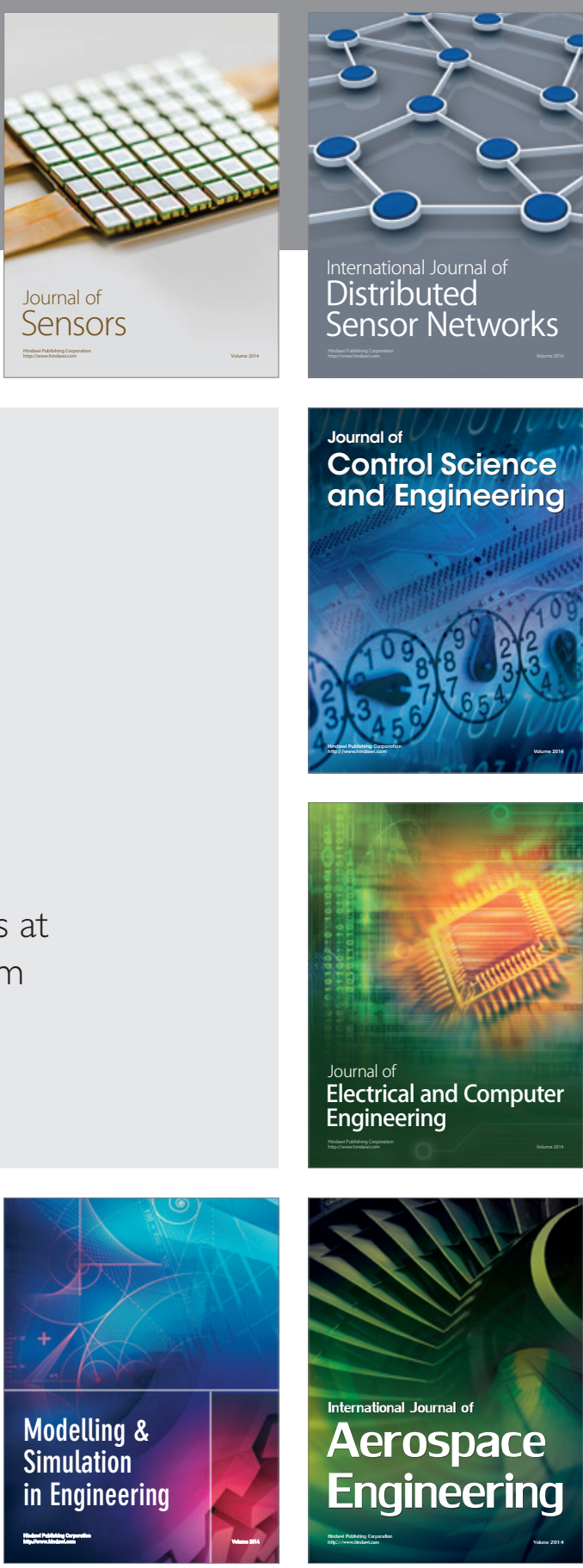

International Journal of

Distributed

Sensor Networks

Journal of

Control Science

and Engineering
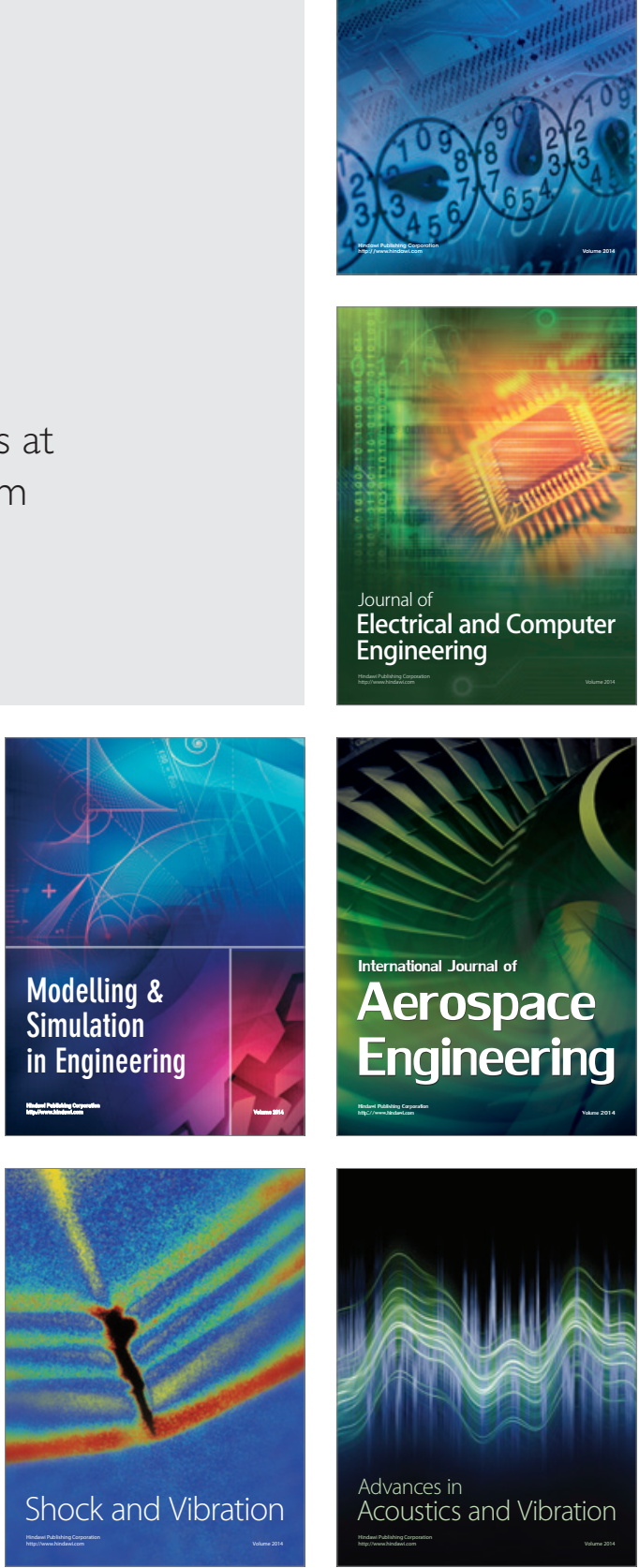